\title{
Iron(III) photoinduced degradation: Catalytic method for 4,4'-diaminostilbene-2,2'-disulfonic acid removal from water
}

\author{
Pascal Wong-Wah-Chung, Gilles Mailhot, and Michèle Bolte ${ }^{\dagger}$ \\ Laboratoire de Photochimie Moléculaire et Macromoléculaire, 24 avenue des Landais, \\ Université Blaise Pascal, CNRS, UMR 6505, F-63177 Aubière Cedex, France
}

\begin{abstract}
The Fe(III)-photoinduced degradation of 4,4'-diaminostilbene-2,2'-disulfonic acid (DSD), used as a model compound of fluorescent whitening agents, was investigated in aqueous solution. The mixing of DSD and iron(III) solutions immediately led to DSD degradation into two oxidation products 5-amino-2formyl-benzene sulfonic acid (1) and DSD epoxide (2) together with the formation of Fe(II). The behaviour of the latter solution was investigated under monochromatic excitation at $365 \mathrm{~nm}$. The irradiation of the solution resulted in a photoredox process that yielded $\mathrm{Fe}(\mathrm{II})$ and $\mathrm{HO}^{\bullet}$ radicals; $\left[\mathrm{Fe}\left(\mathrm{H}_{2} \mathrm{O}\right)_{5}(\mathrm{OH})\right]^{2+}$ being the most photoactive species. The disappearances of the oxidation products were shown to only involve the attack of $\mathrm{HO}^{\bullet}$ radicals; the quantum yields of disappearances are wavelength dependent as the formation of the hydroxyl radicals is. For prolonged irradiation, the total mineralisation of the oxidation products was achieved with the formation of sulphate and ammonium ions. The half-lives of products 1 and 2 when submitted to such a process under solar irradiation were estimated to be respectively 12 and $11 \mathrm{~min}$ in the mixture with $100 \%$ of monomeric species $\left[\mathrm{Fe}\left(\mathrm{H}_{2} \mathrm{O}\right)_{5}(\mathrm{OH})\right]^{2+}$. Under these conditions, the total mineralisation is reached within 2 days of exposure.
\end{abstract}

\section{INTRODUCTION}

4,4'-diaminostilbene-2,2'-disulfonic acid (DSD) is an important intermediate in the synthesis of a great number of fluorescent whitening agents (FWA's).

DSD<smiles>Nc1ccc(C=Cc2ccc(N)cc2S(=O)(=O)O)c(S(=O)(=O)O)c1</smiles>

Consequently, DSD is scattered in non negligible amounts in the aquatic environment and it is present for a relatively long period due to its very poor biodegradability and direct photodegradability. The development of new techniques to eliminate such compounds from water becomes, therefore, important. Recently, Yu et al. [1] improved the biodegradability of DSD by using a pre-treatment with two advanced oxidation processes: Fenton's reagent oxidation and ozonation.

In our laboratory, we have been studying the degradation of various organic and organometallic pollutants photoinduced by Fe(III) for several years [2-4]. This method appeared to be very efficient in terms of degradation of organic compounds due to the formation of hydroxyl radicals $\mathrm{HO}^{\bullet}$ during the photoprocess $[5,6]$.

In a previous study on DSD [7], it was shown that when mixing DSD and Fe(III) a redox reaction appeared

\footnotetext{
† E-mail: michele.bolte@univ-bpclermont.fr
}

in the dark and at room temperature. We observed the complete disappearance of DSD, the formation of two new products together with the reduction of Fe(III) into $\mathrm{Fe}$ (II). One of them was identified as 5-amino-2-formylbenzene sulfonic acid (1) by NMR and LC/ES/MS analysis and the second one was the epoxide derivative (2).<smiles>Nc1ccc(C=O)c(S(=O)(=O)[O-])c1</smiles>

(1)<smiles>Nc1ccc(C2OC2c2ccc(N)cc2S(=O)(=O)[O-])c(S(=O)(=O)[O-])c1</smiles>

(2)
The precise characterisation of each epoxide isomer was not achieved and the so called epoxide corresponds to both isomers.

Because our starting motivation was the removal of DSD from water, we investigated the degradation of DSD oxidation products photoinduced by Fe(III) in aqueous solution. The study of the process in wellcontrolled conditions in terms of excitation wavelength, $\mathrm{pH}$ and $\mathrm{Fe}(\mathrm{III})$ speciation allows us to estimate the half-life of products $\mathbf{1}$ and $\mathbf{2}$ in the environment when they undergo this process. The photodegradation of those products under solar light in the presence of $\mathrm{Fe}$ (III) was also performed in order to obtain their total mineralisation and to check the validity of the previous calculations. 


\section{EXPERIMENTAL}

2.1. Reagents. 4,4'-diaminostilbene-2,2'-disulfonic acid (trans-DSD) was an Across product (95\%) used without further purification. Perchloric acid was a Merck product. Ferric perchlorate nonahydrate $\left[\mathrm{Fe}\left(\mathrm{ClO}_{4}\right)_{3}, 9 \mathrm{H}_{2} \mathrm{O} ; 97 \%\right]$ was a Fluka product kept in a dessicator. The Fe(III) solutions were prepared by diluting stock solution $\left(2.0 \times 10^{-3} \mathrm{M}\right.$ in $\left.\mathrm{Fe}\left(\mathrm{ClO}_{4}\right)_{3}, 9 \mathrm{H}_{2} \mathrm{O}\right)$ to the appropriate $\mathrm{Fe}(\mathrm{III})$ concentration. All the solutions were prepared with ultrapure aerated water (Millipore $\alpha \mathrm{Q}$, resistivity $=18.2 \mathrm{M} \Omega \mathrm{cm}$ ). The $\mathrm{pH}$ measurements were carried out with an Orion pHmeter to 0.1 unit. The ionic strength was not controlled.

2.2. Apparatus and procedures. Monochromatic irradiations at 313, 334 and $365 \mathrm{~nm}$ were carried out with a high-pressure Hg lamp (OSRAM HBO 200 W) and a grating monochromator (Bausch and Lomb). The beam was parallel and the reactor was a cylindrical quartz cell ( $2 \mathrm{~cm}$ length). The photon flux was measured by ferrioxalate actinometry [8].

A high-pressure Hg lamp (Philips HPW 125 W), giving an emission at $365 \mathrm{~nm}$ was located at a focal axis of an elliptical stainless steel container used for kinetic experiments. The reactor, a water-jacketed Pyrex tube was centred at the other focal axis. The reaction medium was continuously stirred. The unit provided illumination $\left(\mathrm{I}_{0}=4.6 \times 10^{15}\right.$ photons $\left.\mathrm{s}^{-1} \mathrm{~cm}^{-3}\right)$ of a large volume of solution $(60 \mathrm{~mL})$.

HPLC experiments were carried out by using a Waters chromatograph equipped with a Waters 996 photodiode array detector giving the UV-visible spectrum at any time. The chromatographic separation was performed with a reverse-phase column Waters Spherisorb ODS2 $\mathrm{C}_{18}$ of $25 \mathrm{~cm}$ length (particle diameter $5 \mu \mathrm{m}$ ). The eluent was water with $\mathrm{HClO}_{4}$ and the flow rate was $1 \mathrm{~mL} \mathrm{~min}{ }^{-1}$. The acidification (with $\mathrm{HClO}_{4}, \mathrm{pH}=3.4$ ) of the eluent permitted good conditions of separation.

UV-visible spectra were recorded with a Cary 3 double beam spectrophotometer. The concentration of the Total Organic Carbon in the aqueous solution was followed on a Shimadzu TOC 5050A analyser. The determinate value was the average of three injections.

The concentrations of sulphate and ammonium ions were measured by capillary electrophoresis on an ion chromatograph Waters Quanta 4000 equipped with a Shimadzu integrator.

2.3. Analysis. The concentration in the aldehydic derivative product $\mathbf{1}$ was measured from the pure isolated product. All attempts to isolate product $\mathbf{2}$ failed, it decomposed when the aqueous solution was evaporated to dryness. The concentration in product 2 was calculated as the difference $[D S D]_{0}-[\mathbf{1}]$, products 1 and 2 being the only products arising from DSD degradation. So, calibration curves were established for both compounds. In addition, product 2 abatement in aqueous solution was measured assuming that (values of both isomers at the detection wavelength in HPLC $\left(\lambda_{\text {detection }}=250 \mathrm{~nm}\right)$ were analogous.

Fe(II) concentration was determined by complexometry with ortho-phenanthroline, using $\varepsilon_{510}=$ $1.118 \times 10^{4} \mathrm{M}^{-1} \mathrm{~cm}^{-1}$ for the $\mathrm{Fe}(\mathrm{II})$-phenanthroline complex [8].

The monomeric concentration of Fe(III) species, i.e., $\left[\mathrm{Fe}(\mathrm{OH})^{2+}\right]$ (which refers to $\left[\mathrm{Fe}\left(\mathrm{H}_{2} \mathrm{O}\right)_{5}(\mathrm{OH})\right]^{2+}$ ), was determined by using the modified [9] Kuenzi's procedure [10]. The concentrations of monomeric Fe(III) species were determined by complexometry with 8hydroxyquinoline-5-sulfonic acid (HQSA). Percentage of monomeric species was defined as:

$$
\% \mathrm{Fe}(\mathrm{OH})^{2+}=\left[\mathrm{Fe}(\mathrm{OH})^{2+}\right] \times 100 /\left[\mathrm{Fe}^{3+}\right]_{\text {tot }} .
$$

The kinetics of the oxidation product degradation were determined by high performance liquid chromatography analysis $\left(\lambda_{\text {detection }}=250 \mathrm{~nm}\right.$ ); the values of the initial quantum yield disappearance of 1 and 2 were calculated from the concentration as a function of irradiation time at conversion percentage lower than $10 \%$.

\section{RESULTS}

3.1. Characterisation of the mixture DSD-Fe(III). When DSD was mixed with an excess of Fe(III), it was immediately transformed into 5-amino-2-formylbenzene sulfonic acid (1) and DSD epoxide (2). The relative concentrations of $\mathbf{1}$ and $\mathbf{2}$ depended on the concentration in $\mathrm{Fe}(\mathrm{OH})^{2+}$. The conditions used to follow the photodegradation of the starting DSD were the following ones: DSD $\left(3.4 \times 10^{-5} \mathrm{M}\right), \mathrm{Fe}(\mathrm{OH})^{2+}(3.0 \times$ $\left.10^{-4} \mathrm{M}\right)$ that led to $3.8 \times 10^{-5} \mathrm{M}$ in product 1 and $1.5 \times 10^{-5} \mathrm{M}$ in product 2 . The solution also contained iron as $\mathrm{Fe}(\mathrm{II})\left(9.5 \times 10^{-5} \mathrm{M}\right)$ and monomeric species $\mathrm{Fe}(\mathrm{OH})^{2+}\left(1.8 \times 10^{-4} \mathrm{M}\right)$. Under these conditions, 90\% of remaining $\mathrm{Fe}(\mathrm{III})$ concentration is present under the monomeric form which is the most photoactive species in terms of hydroxyl radicals production.

This solution is quite stable in the dark and at room temperature in our conditions; only a very slow reaction appears leading to the formation of product $\mathbf{1}$ by the further oxidation of epoxide 2 by Fe(III). Nevertheless, this reaction was negligible in our time scale.

3.2. Photochemical behaviour. The photochemical behaviour was first investigated on each product separately. All attempts to detect any complexation between the oxidation products and $\mathrm{Fe}(\mathrm{OH})^{2+}$ in the solution failed; the difference spectrum between the mixture and Fe(III) solutions corresponded to the sum of the two oxidation products with their respective concentrations. 


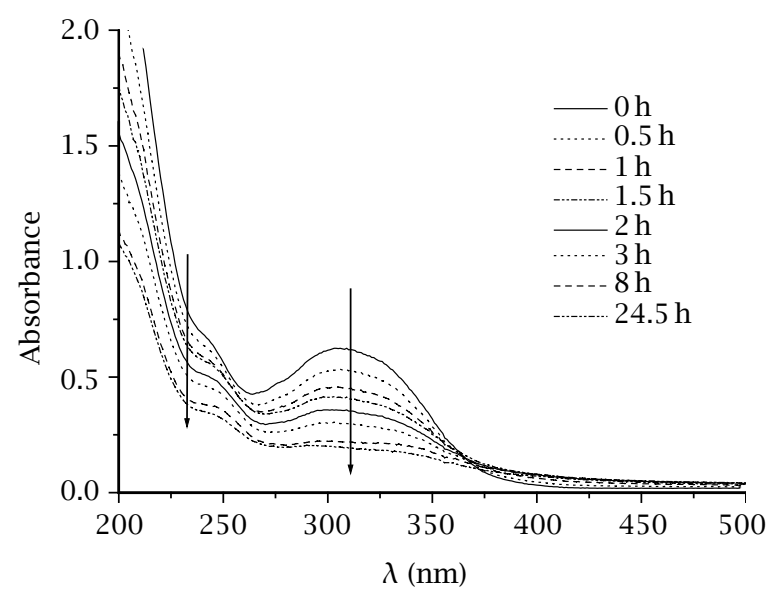

Figure 1. Evolution of DSD-Fe(III) UV-visible absorption spectra upon irradiation at $365 \mathrm{~nm}$.

Kinetic measurements. The irradiations were performed at 313, 334 and $365 \mathrm{~nm}$ representative of solar emission and energetic enough to provok the photochemical process.

The irradiation at $365 \mathrm{~nm}$ of the solution containing $\mathrm{Fe}(\mathrm{OH})^{2+}$ and products 1 and 2 resulted in a continuous decrease in absorbance all along the spectrum reflecting the disappearances of Fe(III) and products $\mathbf{1}$ and 2 (Figure 1); a similar result was obtained for irradiations at 313 and $334 \mathrm{~nm}$.

The disappearance quantum yields $(\Phi)$ of $\mathbf{1}$ and 2 were determined in the presence of oxygen for irradiation at 313, 334 and $365 \mathrm{~nm}$. The results, which are summarised in Table 1, show that the disappearance quantum yields of both products are strongly wavelength dependent: the lower the wavelength, the faster the degradation is. This effect has to be related to the increase of the quantum yield of $\mathrm{HO}^{\bullet}$ radical formation when the excitation wavelength decreases. It is in agreement with the notion that the ejection of $\mathrm{HO}^{\bullet}$ radical from the solvent cage requires kinetic energy [11, 12]. In the presence of 2-propanol (2\%,v/v) taken as a scavenger of $\mathrm{HO}^{\bullet}$ radicals, the degradations of 1 and 2 were totally inhibited (Figure 2). This result confirmed that both degradations are only due to $\mathrm{HO}^{\bullet}$ radicals produced upon irradiation of Fe(III) in aqueous solution; these species are the only radical species generated in the early stages of the photoreaction.

Formation of Fe(II). The formation of Fe(II) was determined by complexometry. The concentration of

Table 1. Quantum yield disappearance of 1 and 2 in aerated solutions.

\begin{tabular}{lcc}
\hline$\lambda(\mathrm{nm})$ & $\begin{array}{c}\Phi_{\text {disappearance }} \\
(\mathbf{1})\left(\times 10^{-2}\right)\end{array}$ & $\begin{array}{c}\Phi_{\text {disappearance }} \\
(2)\left(\times 10^{-2}\right)\end{array}$ \\
\hline 313 & $1.7 \pm 0.2$ & $1.7 \pm 0.2$ \\
334 & $1.3 \pm 0.1$ & $1.2 \pm 0.1$ \\
365 & $0.13 \pm 0.02$ & $0.38 \pm 0.04$ \\
\hline
\end{tabular}

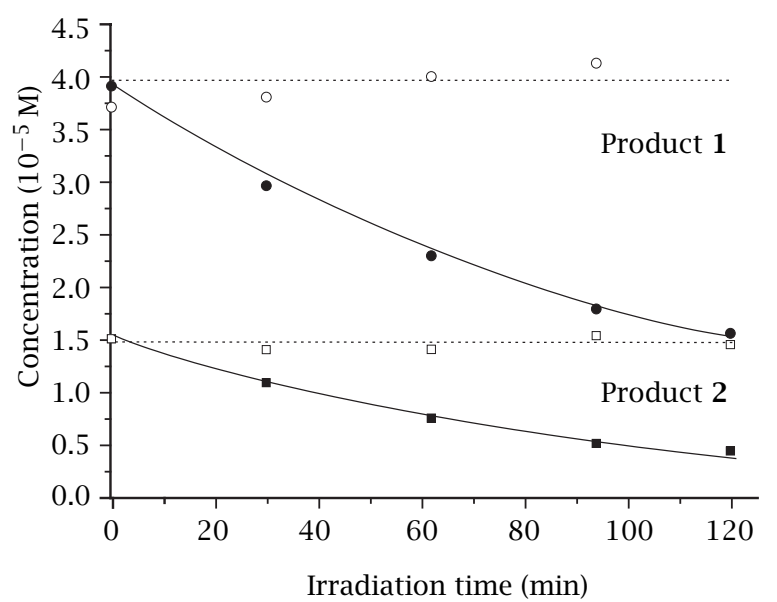

Figure 2. Decrease in 1 and 2 concentrations upon irradiation at $365 \mathrm{~nm}$ measured by HPLC respectively in the presence $(0, \square)$ and in the absence of 2-propanol $(\bullet, \boldsymbol{\bullet})$ in a mixture of DSD-Fe(III) $\left(3.4 \times 10^{-5} \mathrm{M}-3.0 \times 10^{-4} \mathrm{M}\right.$, around $100 \%$ of monomeric species).

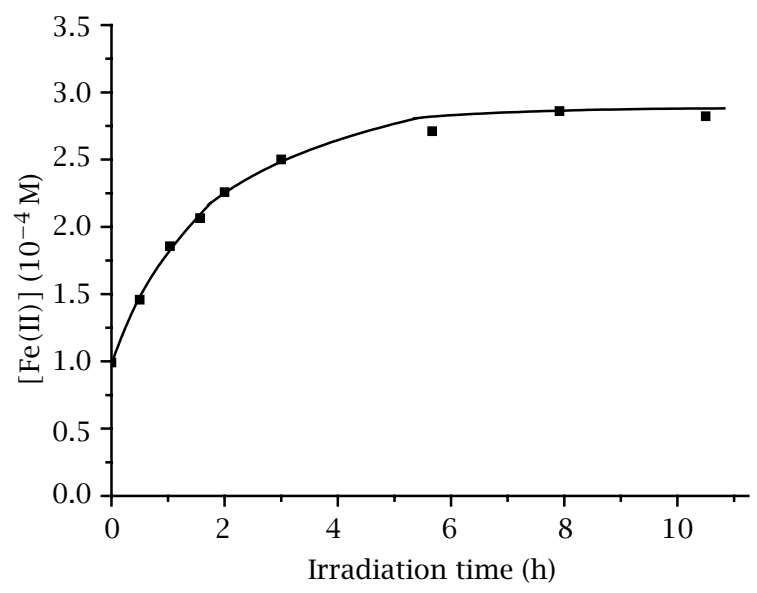

Figure 3. Kinetic of $\mathrm{Fe}(\mathrm{II})$ formation as a function of irradiation time at $365 \mathrm{~nm}$ in aerated solution in a mixture of DSD-Fe(III) $\left(3.4 \times 10^{-5} \mathrm{M}-3.0 \times 10^{-4} \mathrm{M}\right.$, around $100 \%$ of monomeric species).

Fe(II) quickly rose, then reached a constant value upon continued irradiation (Figure 3); this value corresponds, within the experimental errors, to the initial concentration of $\mathrm{Fe}(\mathrm{OH})^{2+}$.

\subsection{DSD degradation and mineralisation.}

Mineralisation upon irradiation at $365 \mathrm{~nm}$. The disappearances of aldehyde $\mathbf{1}$ and epoxide 2 and the removal of the total organic carbon were followed in a mixture of DSD-Fe(III) upon irradiation at $365 \mathrm{~nm}$.

The decreases in $\mathbf{1}$ and $\mathbf{2}$ concentrations were measured by HPLC for irradiation at $365 \mathrm{~nm}$; their kinetics are represented on Figure 4. Several peaks were 

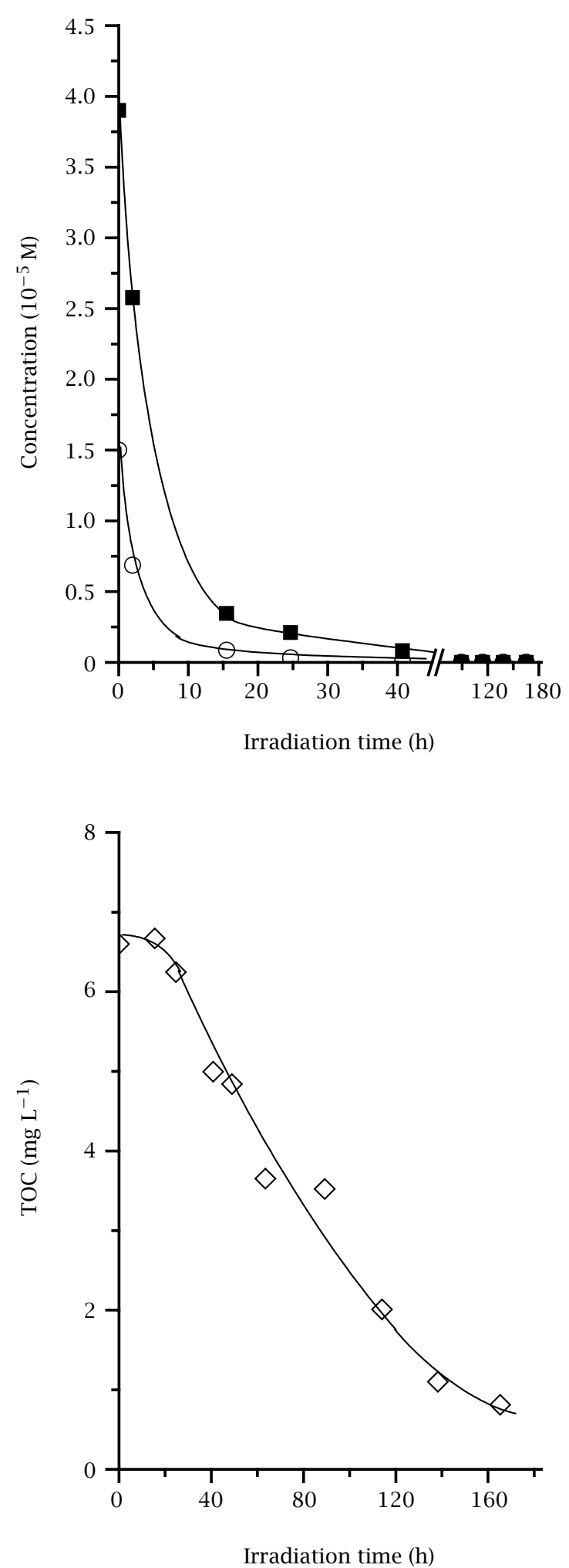

Figure 4. Kinetics of product 1 (-) and 2 (०) and evolution of TOC $(\diamond)$ in a mixture of DSD-Fe(III) $\left(3.4 \times 10^{-5} M-3.0 \times\right.$ $10^{-4} \mathrm{M}$, around $100 \%$ of monomeric species) irradiated at $365 \mathrm{~nm}$. observed from the beginning of the irradiation; these photoproducts, with high polarity appeared nevertheless in very low amount due to their possible fast further degradation and low stability. All the attempts to isolate them failed. In less than $40 \mathrm{~h}$ of exposure, the products 1 and 2 completely disappeared and only $25 \%$ of the initial carbon have been transformed into $\mathrm{CO}_{2}$; the mineralisation is achieved in around $200 \mathrm{~h}$ of irradiation (Figure 4). The decrease in TOC is observed with an induction period of $15 \mathrm{~h}$ due to the formation of organic photoproducts. The mineralisation process appeared to begin when products $\mathbf{1}$ and $\mathbf{2}$ were completely degraded and some photoproducts significantly degraded: around $94 \%$ of 1 and 2 and around 50\% of the major aromatic photoproducts.

Formation of sulphate and ammonium ions. The kinetics of formation of sulphate and ammonium ions were also followed in the same mixture of DSD-Fe(III) upon irradiation at $365 \mathrm{~nm}$; they are represented on Figure 5. The concentration of sulphate ions quickly rose after a short induction period $(20 \mathrm{~min})$ shorter than that observed with TOC evolution (20 h, Figure 4); on the contrary, the release of ammonium is observed from the beginning of the irradiation but in lower concentration. It is worth mentioning that neither nitrate nor nitrite ions were observed during the irradiation of the mixture.

The formation of sulfate and ammonium ions can be attributed to the degradation of products 1 and 2 . When 1 was photodegraded alone with iron (III), the formation of ammonium ions presents a short induction period; accordingly, the initial formation of $\mathrm{NH}_{4}{ }^{+}$ions in the mixture of $\mathbf{1}$ and $\mathbf{2}$ is due to the presence of DSD epoxide 2.

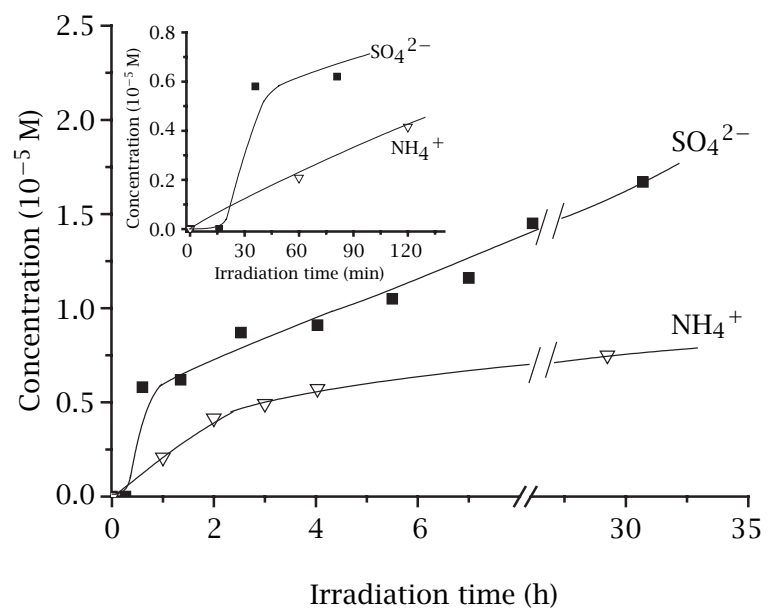

Figure 5. Kinetics of sulphate (घ) and ammonium ( $\nabla)$ ions in a mixture of DSD-Fe(III) $\left(3.4 \times 10^{-5} M-3.0 \times 10^{-4} M\right.$, around $100 \%$ of monomeric species) irradiated at $365 \mathrm{~nm}$. 


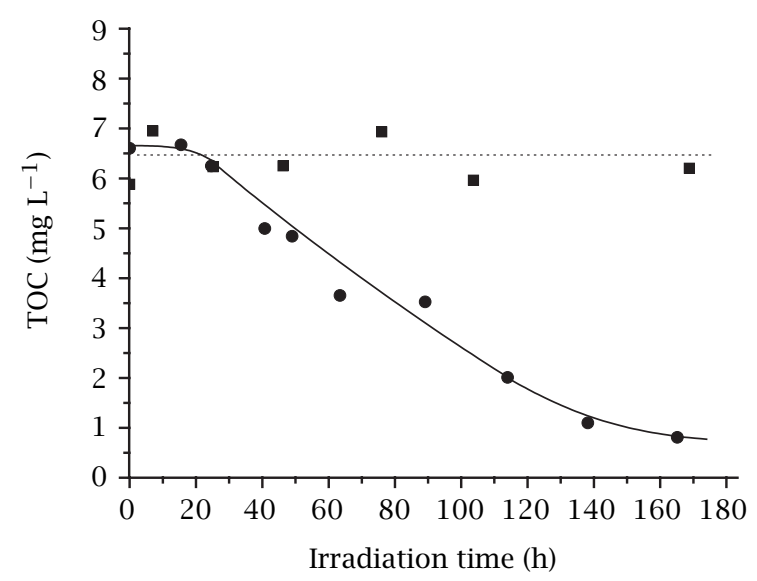

Figure 6. Evolution of TOC in a mixture of DSD-Fe(III) (•) $\left(3.4 \times 10^{-5} \mathrm{M}-3.0 \times 10^{-4} \mathrm{M}\right.$, around $100 \%$ of monomeric species) and in a solution of DSD at the same concentration (匹), both irradiated at $365 \mathrm{~nm}$ and at $\mathrm{pH}=3.4$.

Efficiency of the system Fe(III)/UV. In order to confirm the involvement and the efficiency of Fe(III) species in the photodegradation of the oxidation products, we followed the evolution of TOC in a solution of DSD in similar conditions $\left(3.4 \times 10^{-5} \mathrm{M}\right.$ and $\left.\mathrm{pH}=3.4\right)$ but in the absence of Fe(III). In this case, after 7 days of irradiation, no mineralisation of DSD was observed whereas in the presence of Fe(III), 90\% of the initial organic carbon has been transformed into $\mathrm{CO}_{2}$ (Figure 6). This observation confirms that the system Fe(III)/UV could be used in order to completely achieve the removal of DSD and its oxidation products from waters.

\subsection{Irradiation under solar light and projec-} tion to environment. To show the relevance of the method, we followed the disappearance of products $\mathbf{1}$ and 2 and also the abatement of TOC under solar irradiation. A mixture of DSD-Fe(III) was exposed to solar light during sunny days in May 2001 at ClermontFerrand (Figure 7 ). After $5 \mathrm{~h}$ of irradiation, the oxidation products 1 and 2 completely disappeared; this fast degradation took place without any visible induction period in the TOC evolution. The photoproducts were similar to those observed upon irradiation at $365 \mathrm{~nm}$. After $39 \mathrm{~h}$ of exposure ( $60 \mathrm{~h}$ day and night), the total mineralisation is reached. Under solar irradiation, the lack of an induction period in the transformation of the oxidation products into $\mathrm{CO}_{2}$ can be accounted for the short wavelengths present in the solar emission, hydroxyl radicals being more efficiently formed which results in a faster mineralisation. The life-time of products 1 and 2 in a mixture of DSD-Fe(III) $\left(3.4 \times 10^{-5} \mathrm{M}\right.$ $3.0 \times 10^{-4} \mathrm{M}$, around $100 \%$ of monomeric species) was estimated experimentally from the results obtained under solar light irradiation. The half-lives are equal to 12 and 11 min for products 1 and 2, respectively.
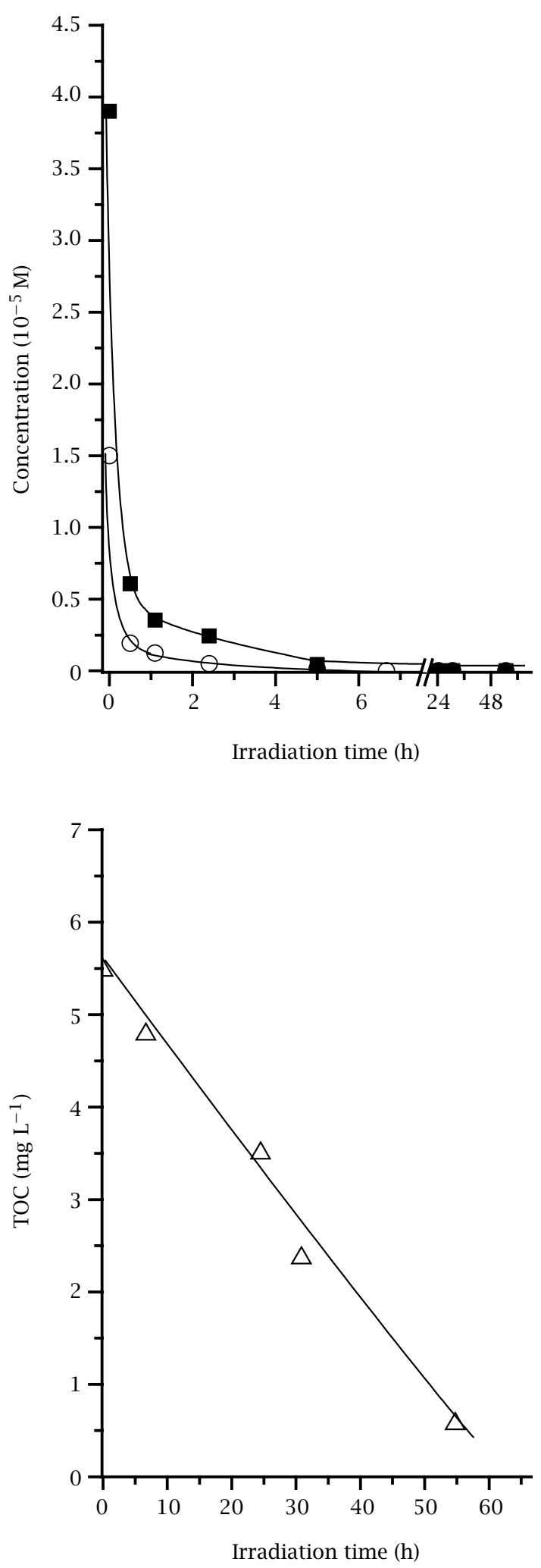

Figure 7. Kinetics of product 1 (ם) and 2 (०) elimination and evolution of TOC $(\triangle)$ in a mixture of DSD-Fe(III) $(3.4 \times$ $10^{-5} \mathrm{M}-3.0 \times 10^{-4} \mathrm{M}$, around $100 \%$ of monomeric species) irradiated under solar light. 


\section{CONCLUSION}

The reported results show that the redox reaction observed in the presence of iron(III) is an efficient process for DSD removal from wastewaters; the combination with the attack by $\mathrm{HO}^{\bullet}$ radicals coming from the photoredox process leads to the total mineralisation of the decomposition compounds due to the continuous formation of hydroxyl radicals in the photocatalytic redox system Fe(III)/Fe(II) [9, 12]. The complete mineralisation of DSD is reached in less than 2 days exposure in our experimental conditions. This method is of interest because it permits first to completely degrade a high refractory compound such as DSD by using low concentration in $\mathrm{Fe}(\mathrm{III})$ compatible with a safe environment and secondly to use solar light as the energy source.

\section{REFERENCES}

[1] G. Yu, W. Zhu, and Z. Yang, Chemosphere 37 (1998), 487.

[2] P. Mazellier, M. Sarakha, and M. Bolte, New J. Chem. 23 (1999), 133.
[3] N. Brand, G. Mailhot, G. Sarakha, and M. Bolte, J. Photochem. Photobiol. A: Chem. 135 (2000), 221.

[4] P. Mazellier, G. Mailhot, and M. Bolte, New J. Chem. 21 (1997), 389.

[5] F. S. Dainton and M. Tordoff, Trans. Faraday Soc. 53 (1957), 666.

[6] B. C. Faust and J. Hoigné, Atmos. Environ. A 24 (1990), 79.

[7] P. Wong-Wah-Chung, Ph.D. thesis, ClermontFerrand, France, 2001.

[8] J. G. Calvert and J. M. Pitts, Photochemistry, John Wiley and Sons, New York, 1966, p. 783.

[9] N. Brand, G. Mailhot, and M. Bolte, Environ. Sci. Technol. 32 (1998), 2715.

[10] W. H. Kuenzi, Ph.D. thesis, Zurich, Switzerland, 1982.

[11] H.-J. Benkelberg and P. Warneck, J. Phys. Chem. 99 (1995), 5214.

[12] H. Kawaguchi and A. Inagaki, Chemosphere 27 (1993), 389. 


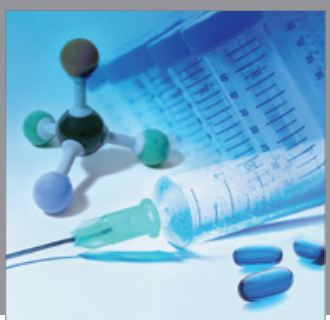

International Journal of

Medicinal Chemistry

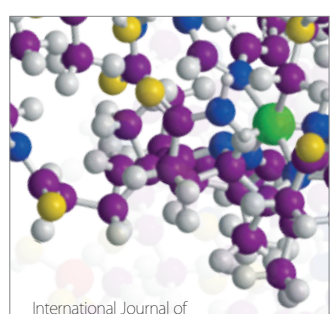

Carbohydrate Chemistry

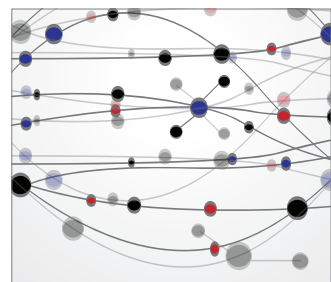

The Scientific World Journal
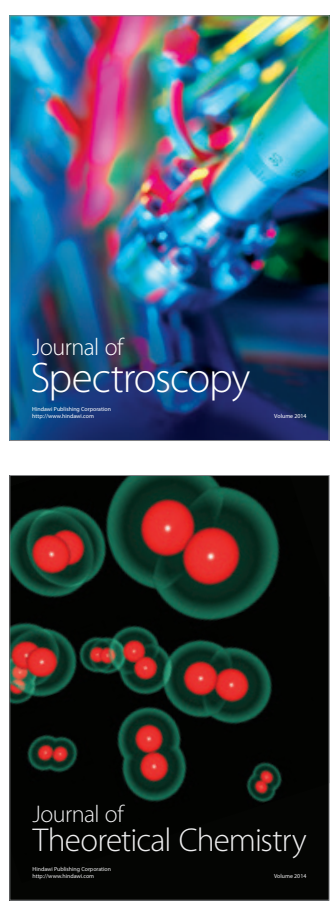
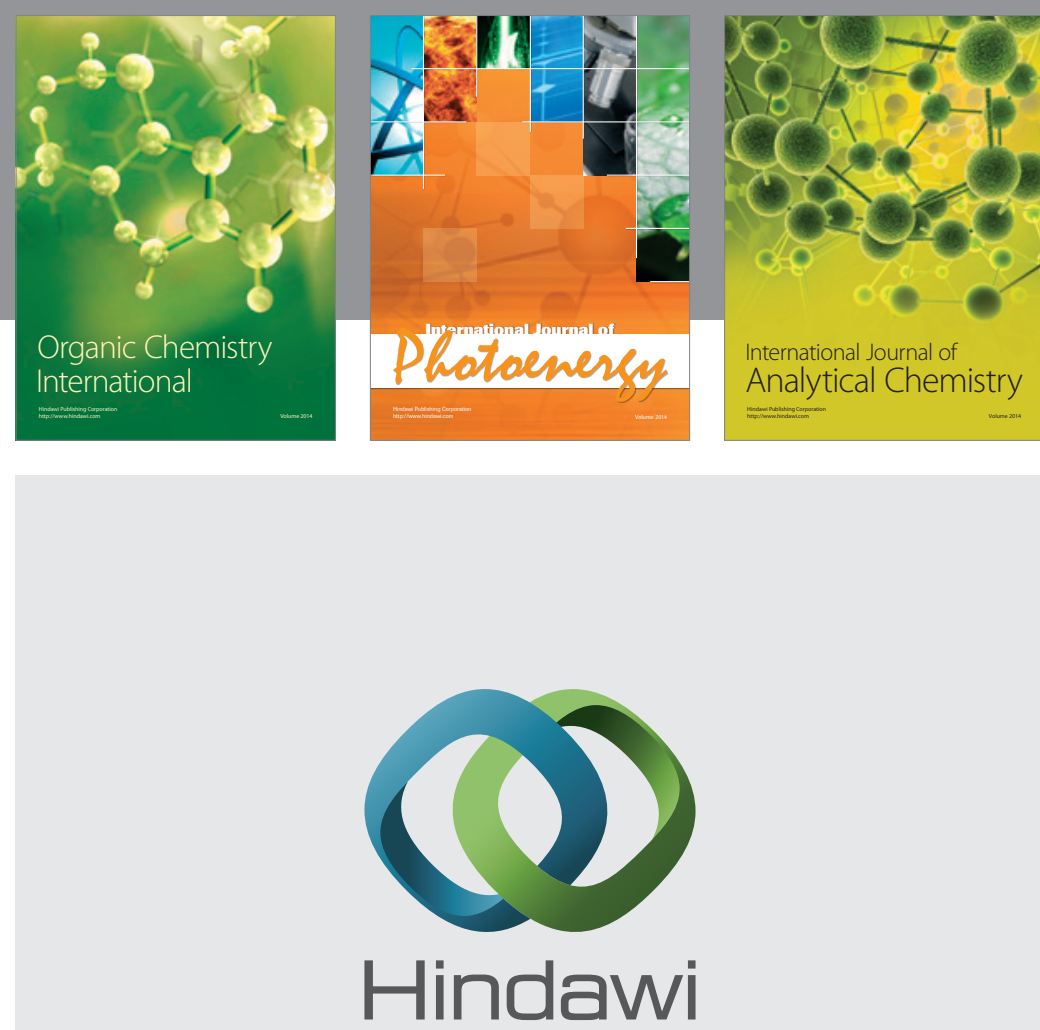

Submit your manuscripts at

http://www.hindawi.com
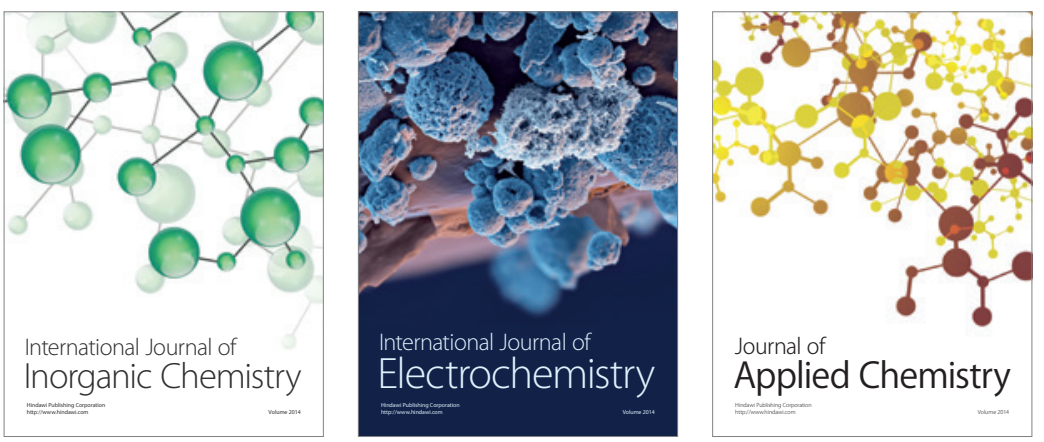

Journal of

Applied Chemistry
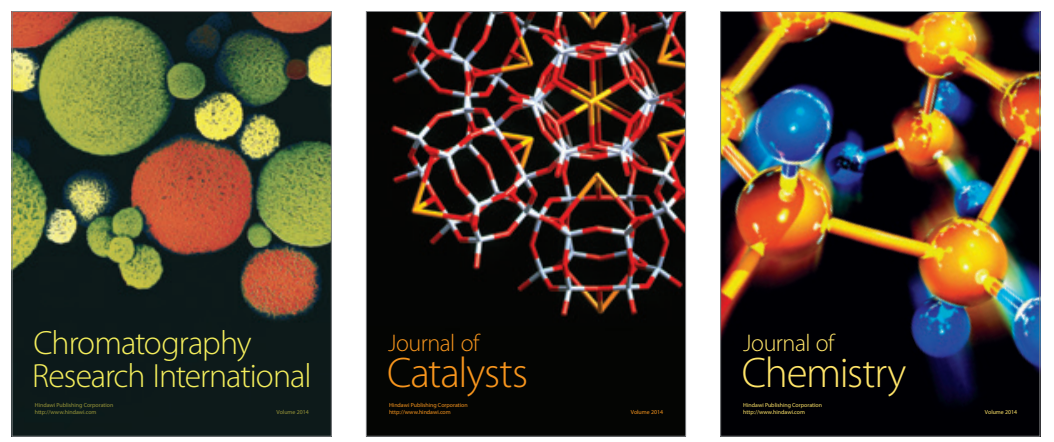
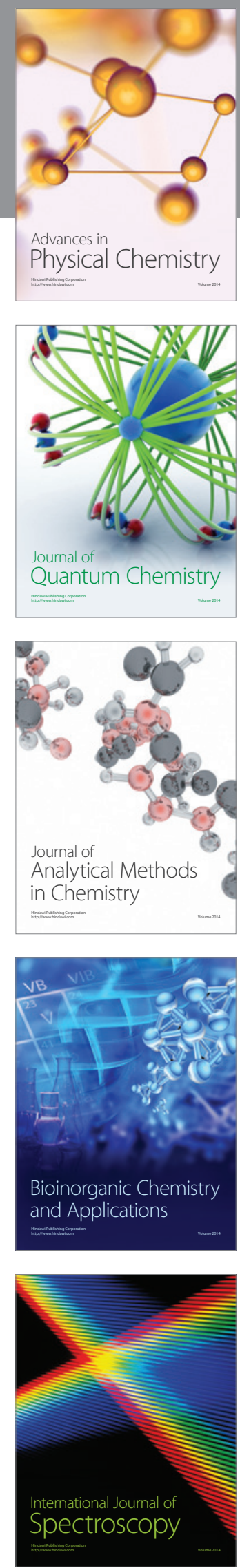